\title{
Negative affective states and their effects on morbidity, mortality and longevity
}

\author{
MD Walker*, G Duggan, N Roulston, A Van Slack and G Mason
}

Animal and Poultry Science, University of Guelph, Guelph, Ontario NIG 2WI, Canada

* Contact for correspondence and requests for reprints: mwalke04@uoguelph.ca

\begin{abstract}
Mortality rates are often used in population-level animal welfare assessments because they are assumed to reflect rates of disease or injury and other problems likely to cause poor welfare. High mortality is thus assumed to correlate with factors likely to cause negative affective states. Here, we argue that negative affective states are also related to mortality rates more directly, via causal rather than merely correlational routes. In humans, negative affective states predict elevated morbidity and mortality rates as well as decreased longevity, while self-reported happiness does the opposite. This review investigates whether mortality rates and longevity can thus be used to make inferences regarding past affective states in animals. The proposed mechanism is that chronic stressors cause negative affective states and thence harmful physiological consequences through continual activation of the hypothalamicpituitary-adrenal and sympathetic-adreno-medullary axes, which in turn can lead to increased mortality. The convergent validity of mortality as an indicator of past negative affect is demonstrated via examples of how stressors such as bereavement in humans and social isolation in social non-human species cause negative affective states, and then increase the morbidity of potentially lethal conditions such as cardiovascular disease, cancer and HIVIAIDS, ultimately leading to increased mortality and reduced longevity in both humans and animals. The potential drawbacks of using mortality rates to infer animal welfare are also discussed, including its low sensitivity and the multiplicity of factors unrelated to affective states that can influence mortality rates. However, providing these issues are accounted for, it is suggested that this indicator has value in welfare assessment, and is especially well suited for cases where animals are allowed to live out their natural lifespans, such as tends to be the case with zoo and companion animals.
\end{abstract}

Keywords: animal welfare, longevity, morbidity, mortality, negative affect, stressors

\section{Introduction}

Human happiness, as assessed by self-reported life satisfaction, optimism, and positive emotion, is linked to how long individuals live: happier people live longer (eg Deiner \& Chan 2011). In contrast, self-reported depression is correlated with increased mortality rates, independent of physical health (eg Rovner et al 1991). This phenomenon may be applicable to animals as well. Classic early work by von Holst (1972), for example, revealed that subordinate male tree shrews (Tupaia belangeri) had higher mortality rates after being repeatedly physically subjugated by a dominant male. More recently, in zoo orangutans (Pongo abelii and P. pygmaeus), individuals that were subjectively judged to be happier were shown to subsequently live longer than those who were deemed less happy (Weiss et al 2011), while in pet dogs (Canis lupus familiaris), those with a fear of strangers lived significantly shorter lives than bolder/more confident conspecifics (Dreschel 2010). These studies suggest that negative affect is correlated with higher mortality and reduced longevity in both humans and animals. Granted, the use of mortality rates to indicate poor health and thus poor welfare in a population is not new: collecting data on on-farm mortality rates is a standard part of Welfare Quality ${ }^{\circledR}$ procedures (eg Chauvin et al 2011). However, in these instances, negative affective states (or poor welfare states) are assumed to be correlates of mortality rate, by being induced by the causes of the elevated mortality (eg high rates of disease, or poor nutrition). This review will explore an alternative link between mortality and negative affect: that negative affective states actually play a causal role in increasing mortality rates. One possible mechanism is that lasting negative affective states cause persistent activation of, or changes in, the body's stress responses resulting in increased morbidity and mortality (eg Dreschel 2010; Weiss et al 2011). This has been modelled in Figure 1. Some animal researchers have therefore begun using mortality rates to assess the affective impact of potentially stressful habitats or situations that animals experienced while they were alive (eg Clubb et al 2008, 2009; Mason \& Veasey 2010).

First, we give some definitions. The affective state of an animal or person refers to their experienced feelings, moods or emotions (eg Russell 2003). These can be divided into 


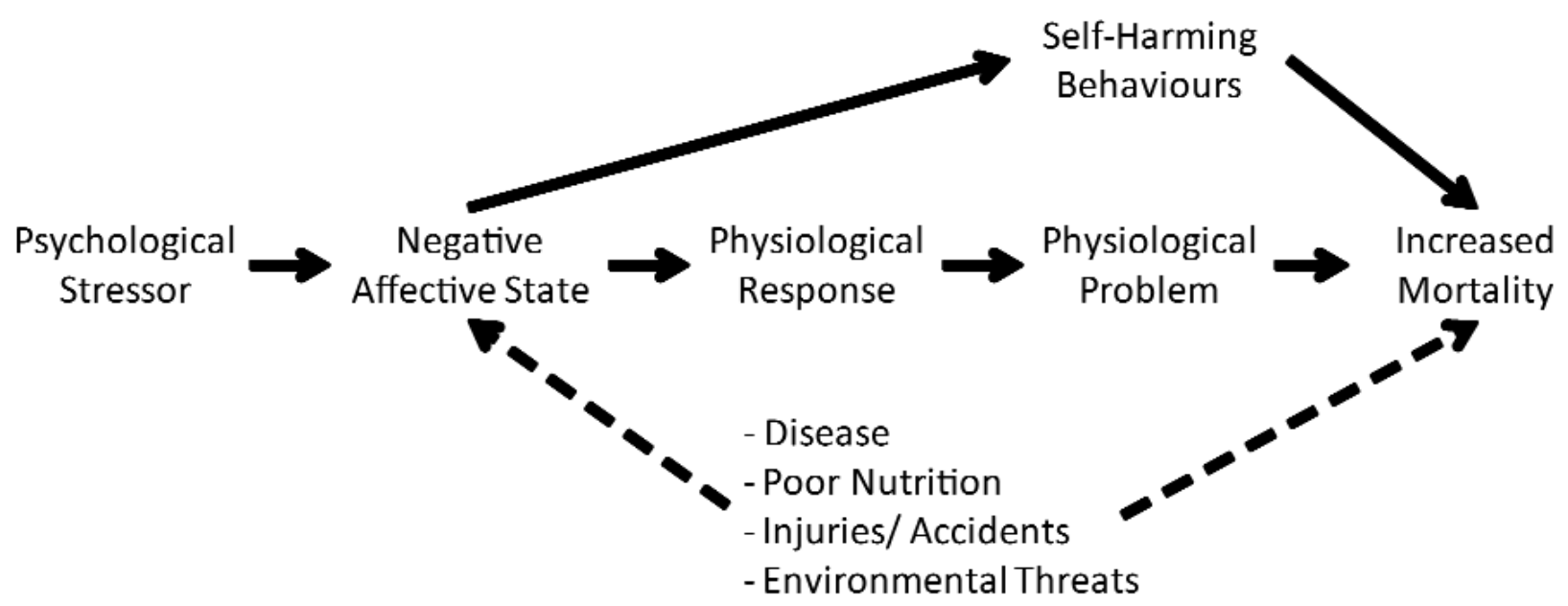

Conceptual model of how stressors may play a causal role in increasing mortality. The solid black arrows represent the causal relationships explored in this review. The dashed-line arrows show the pathways typically implicated when mortality rates are used in welfare assessment, where negative affective states are correlated with increased mortality.

Table I Definitions of terms relating to health and ageing.

\begin{tabular}{ll}
\hline Term & Definition \\
\hline Morbidity & $\begin{array}{l}\text { The incidence and/or prevalence of a disease in a } \\
\text { population over a given unit of time (eg Jacob et al 2005) }\end{array}$ \\
Mortality & $\begin{array}{l}\text { The ratio of deaths in a sample population to the } \\
\text { number of individuals in that population over a }\end{array}$ \\
& $\begin{array}{l}\text { given unit of time (eg Aaltonen et al 2009) } \\
\text { Survivorship }\end{array}$ \\
& $\begin{array}{l}\text { The ratio of survivors in a sample population to the } \\
\text { total number of individuals in that population over a } \\
\text { given unit of time (eg Vigliola \& Meekan 2002) }\end{array}$ \\
Longevity & $\begin{array}{l}\text { How long an organism lives for; lifespan (eg Munoz } \\
\text { \& Riddle 2003) }\end{array}$ \\
Senescence & $\begin{array}{l}\text { The process of growing old, specifically the } \\
\text { accumulation of the deleterious effects of ageing } \\
\text { (eg Saino et al 2002) }\end{array}$ \\
\hline
\end{tabular}

positive or negative categories. Positive affective states (eg joy) are sought after and preferred, while negative affective states (eg fear) are avoided when possible. Here, animal affective states are classified as positive or negative based on evidence compared with established indicators of animal welfare, both behavioural and physiological. The key indicators in animals include approach/avoidance tests (eg Rushen 1986), and assessment of whether a stimulus is a negative or positive reinforcer of learned behaviour (Spruijt et al 2001). Furthermore, supporting evidence comes from other measures, eg hypothalamic-pituitary-adrenal (HPA) axis activity (Tsigos \& Chrousos 2002), and/or sympatheticadreno-medullary (SAM) axis activity (Sinha et al 2003). Stressors are stimuli, real or perceived, that cause negative affective states; these stressors can afflict the subject either physically (eg pain), or purely psychologically (eg death of a loved one). When resulting negative affective states persist, they are representative of chronic suffering (Neugebauer et al 2004). A number of terms are used in this review that concern health and ageing; these are defined for clarity in Table 1 . This paper will primarily review evidence of how a negative affective state caused by stressors can lead to increased morbidity, mortality, and decreased longevity.

For the purposes of this review, animals' welfare is judged solely from affective state. Many argue that how an animal perceives and experiences stimuli is the most important determinant of its welfare; thus affective states are really the essence of welfare, and indeed are what gives welfare its moral urgency (eg Dawkins 1988; Mason \& Mendl 1993; Duncan 2006). As long as individuals are experiencing a positive affective state they are said to have good welfare, and vice versa.

The HPA and SAM axes are both well known to be the physiological responses to stressors (eg HPA axis: Tsigos \& Chrousos 2002; SAM: Sinha et al 2003). However, it should be noted that these indices can be activated by physical activity, as well as positive affective states such as excitement (eg Christensen \& Galbo 1983). Thus, the context in which these indices are being examined is very important and these factors need to be controlled for. Chronic stimulation of these axes may lead to harmful physiological consequences. For example, chronic sympathetic bias can cause shifts in T-helper cell balance, leading to disease, early senescence and otherwise disrupted autonomic activity (Yun et al 2004). Likewise, chronically high levels of cortisol in the bloodstream have been related to numerous human disorders including insulin resistance, cardiovascular disease, immune disturbances, and nervous system disorders (eg McEwen 2005). 
The evidence in this review will examine links between mortality and affective state where possible; and otherwise between affect and certain types of morbidity, namely those where the diseases concerned are highly linked to mortality (eg cardiovascular disease, cancer, HIV/AIDS). Since humans are able to self-report their own affective state, we will closely examine the human literature first, prior to assessing how stressors lead to increased morbidity and mortality in animals. Note that the goal of this review is not to provide an exhaustive list of mechanisms of how stressors can do this, but rather to provide evidence for and against the hypothesis that negative affect can lead to increased morbidity and mortality.

\section{Human cases where negative affect increases mortality}

Humans provide excellent examples because they can report how they feel. It is also easy to identify rewarding and aversive experiences for humans. Furthermore, most of the relevant research comes from careful, often largescale, medical studies where potential confounds are measured and controlled for.

Several cases demonstrate the relationship between overall self-reported affective state and mortality. To expand on an example from the Introduction, Deiner and Chan (2011) review numerous cases of how positive affective states such as optimism, satisfaction with income, enjoyment of life, and happiness are correlated with lower mortality and increased longevity. These effects are evident even after statistically controlling for various confounding factors such as age, sex, smoking, alcohol consumption, and obesity among many more. Similarly, higher levels of self-reported positive affect among HIV + men are correlated with decreased mortality rates, even after correcting for time-dependent covariates such as CD4 levels and anti-retroviral use (Moskowitz 2003). In contrast, elderly people who reported a high level of experienced negative affect were twice as likely to die in the next four years as those with a low level, after controlling for age and health effects (Wilson et al 2003).

Similarly, researchers that have studied specific affective states such as anxiety, depression, and hopelessness have come to similar conclusions. Kawachi et al (1992) conducted a study on a large cohort of nearly 40,000 male healthcare professionals. At the outset, all subjects were free of cardiovascular disease and were assessed for levels of anxiety. By the follow-up two years later, those men with the highest levels of anxiety experienced three times the number of incidences of fatal coronary heart disease than those with the lowest levels of anxiety. This effect could not be accounted for by confounding factors such as smoking, alcohol intake, or a host of other cardiovascular risk factors, leading to the conclusion of a strong causal link between anxiety and risk of fatal coronary heart disease. Depression prior to stroke predicts a more severe stroke, less functional recovery in the short and long term, and higher long-term mortality (Naess et al 2010). Using meta-analyses, the mortality rates in cancer patients were also found to be up to $39 \%$ higher in patients who were also diagnosed with depression, and this effect persisted after adjustment for clinical prognosticators (eg age, sex, smoking status, etc), suggesting that depression may play a true causal role in mortality (Satin et al 2009). Likewise, chronic depression predicts lower levels of CD4 T lymphocytes and increased viral load, both of which contribute to HIV/AIDS disease progression, and also to increased mortality (Leserman 2008). Tellingly, previous work revealed that CD4 cell count and AIDS symptoms did not predict future depression, suggesting that depression leads to a clinical disease change, not the other way around (Leserman 2003). Selfreported hopelessness in elderly humans predicted all-cause mortality after controlling for several confounding factors (eg age, sex, body-mass index, smoking habits, and activity levels). Specifically, deaths due to cardiovascular disease and cancer were significantly higher among hopeless subjects (Stern et al 2001). Hopelessness is also correlated with an increase in fatal incidences of ischaemic heart disease (Anda et al 1993). Such effects were statistically independent of other established risk factors including age, sex, race, smoking, systolic blood pressure, body-mass index, and physical activity, and the authors therefore suggested that hopelessness does indeed play a causal role.

Specific negative experiences can also lead to increased mortality. The classic Whitehall study demonstrated that mortality rates were higher among men in the lower echelons of the British Civil Service hierarchy (Marmot et al 1978). Specifically, men in the lowest grade jobs had 3.6 times higher mortality due to coronary heart disease than men in the highest grade jobs, and the effect was still strong after controlling for risk factors like blood pressure, plasma glucose levels, smoking, and levels of physical activity. Depression is significantly more prevalent in people of lower socioeconomic status (eg Murphy et al 1991), and thus depression in the lowest grade workers may play a role in the results of the Whitehall study. Another example of a negative experience is having low levels of social support. Social support is assessed by determining both the quantity and quality of social relationships and low levels of social support are correlated to depression (Schaefer et al 1981). A lack of social support has been implicated in causing increased mortality in several instances. For example, Berkman et al (1992) found that of 194 elderly men and women hospitalised for acute myocardial infarction (heart attack), 76 died within the next six months, and 59 of those were from cardiovascular disorders. After controlling for several confounding factors it was shown that those patients who had no social support were twice as likely to die as those who reported two or more sources of support. When the analysis is restricted to only those patients who died clearly of cardiac causes, the mortality rate was $45 \%$ among those with no social support, while it was only $19 \%$ among those who had two or more sources of support. Likewise, heart failure outpatients that were depressed or socially isolated had an increased risk of mortality within the next two years after controlling for demographics and clinical status (Friedmann et al 2006). In a retrospective analysis of Union Army veterans, Costa and 
Kahn (2010) show that a strong cohesive social network during stressful wartime events lessens a future probability of having a stroke, of developing cardiovascular disease and atherosclerosis, and subsequently leads to increased longevity. This effect was evident despite controlling for numerous potential confounds including age, rank, wounds received in battle, previous occupation, marital status, body-mass index, and personal wealth. Turning to another form of negative experience, being burgled has also been found to increase mortality among the elderly. Victims (and their families) were interviewed by Donaldson (2003) and were described as becoming 'very twitchy' and more nervous after the crime; their health was also found to deteriorate faster than non-burgled neighbours, matched for age and sex. The effect was so strong that within only two years, victims were 2.4 times more likely to be dead or to be in residential care (due to declining health) than their nonburgled neighbours. This evidence suggests that living in fear of being victimised may play a causal role in increasing mortality among the elderly.

Negative affect and negative life events are thus not only shown to increase mortality rates of peoples who suffer from conditions like cancer and cardiovascular disease, but also of otherwise healthy subjects. Overall, this body of evidence provides strong support for the idea that negative affective states can lead to increased morbidity and mortality in humans.

\section{Mechanisms linking negative affect and mortality in humans}

Three main conditions will be explored here: immunosuppression, cancer and cardiovascular disease. This is not an exhaustive list of the stressor-sensitive diseases and conditions that can influence mortality, but these cases do provide some very clear and relevant examples. Suicide is also added as a final, non-disease link between affect and elevated mortality.

First we look at immunosuppression, as evidenced from a variety of measures, the first one to be discussed being disease prevalence and progression. A large cohort study of humans done by Takkouche et al (2001) examined how affective state influenced the likelihood of becoming ill with the common cold, obviously not fatal, but a typical virus nonetheless. Through questionnaires, the researchers were able to score participants on their affective state, both positive and negative. Subjects with a high index of negative affect showed an incidence rate of 3.7, while subjects with a high index of positive affect showed an incidence rate of only 0.6 in the following year. Similarly, marital quality can have a large impact on physical health (Wickrama et al 1997). Husbands and wives who had been married for at least 14 years both rated their marital quality and physical health through questionnaires yearly for three years. Ultimately, improved marital quality over time predicted increasing physical health for both wives and husbands, and vice versa. These effects were significant after controlling for education, family income, and jobfamily interference. Furthermore, the authors conclude that these effects are purely the result of a psychological stressor, as no influence of marital quality on health-risk behaviours was found. Because wound healing and overall immune function are positively correlated (Kirk et al 1993), it is possible to examine the link between psychological stressors and wound healing as an alternative, somatic indicator of the functioning of the immune system, as was done by Kiecolt-Glaser et al (1995). The study group was comprised of women caring for relatives with dementia, and a control group of females matched for age and income. Through a questionnaire, scientists rated the women's affective state prior to and one week into the study. Caregivers reported significantly more negative affect than controls in both surveys. Each woman was given a punch biopsy with wound examination every $2-8$ days until it had healed. Complete wound healing took significantly longer in the care-giving women than in the controls.

Stressors causing immunosuppression can elevate mortality, as well as having the non-lethal effects outlined above, by increasing the risks of infection by potentially dangerous diseases, and/or by increasing the pathogenesis of diseases. For example, severe stressors (death of a family member, life-threatening illness of a family member, serious assault, and break-up with long term committed partner) among people infected with HIV can increase the risk of early disease progression 2-4 times that of non-stressed individuals, even if that stressor occurs only once in a six-month period (Evans et al 1997). Similarly, experiencing a severe stressor (in this case, death of a juvenile child) significantly increases the risk of developing infection-related cancers for women (Fang et al 2010). In particular, human papillomavirus related cancers (eg cervical cancer) were the most prevalent among women who lost a child. The researchers specifically associate immunosuppression due to this stressor with the development of these cancers, as they have a well-established indication for viral infection.

As we have seen, cancer is a disease in which immunosuppression plays an exacerbatory role (Guba et al 2004). Breast cancer risk is elevated by divorce, death of a husband, death of a close friend, loss of a job, or personal illness/injury after controlling for risk factors such as age, social class, age at first pregnancy, alcohol use, smoking, physical activity, and psychological state prior to the stressor (Lillberg et al 2003). Specifically, there is a positive correlation between the number of stressors experienced and the associated risk of developing breast cancer. Additionally, patients with a more negative reaction to cancer diagnosis have faster disease progression and poorer responses to treatment (Pennix et al 1998). Noradrenaline, adrenaline and cortisol all increase the invasiveness of ovarian cancer cells, although noradrenaline and adrenaline have the greatest impact (Sood et al 2006). This was determined by using ovarian cancer cell cultures in vitro and exposing them to all three hormones separately using the membrane invasion culture system. Furthermore, noradrenaline has been found to also enhance melanoma tumour growth (Yang et al 2009). These data suggest that prolonged or repeated bouts of stressors can directly increase cancer progression, with obvious implications for mortality risk. 
Cardiovascular disease is the third key illness to be adversely affected by negative affect. Thus, the negative affective states of hopelessness, pessimism, anxiety, and anger have all been found to predict adverse cardiovascular events, such as coronary artery disease and myocardial infarction (reviewed by Kubzansky et al 2005). In a study of Finnish men who underwent carotid ultrasonography, those that reported high levels of hopelessness also showed high baseline levels of atherosclerosis and faster progression four years later (Everson et al 1997). Psychosocial stressors (eg financial trouble, depression, perceived disempowerment) have similarly been found to account for approximately $30 \%$ of the attributable risk of myocardial infarction; only lipid status and smoking were more powerfully predictive. Overall, the magnitude of the effect of psychosocial stressors on risk of myocardial infarction is comparable to those of hypertension and abdominal obesity (Rosengren et al 2004). Data implicate the stress-hormone systems; thus, for example, depression is correlated with dysfunction of the HPA axis, while anger has been associated with chronic overstimulation of the sympathetic nervous system, and stimulation of both of these axes negatively impacts coronary heart disease prognosis (Sirois \& Burg 2003).

As a final non-disease mechanism through which negative affective state can elevate mortality in humans, the links between affective states and suicide are well established. For example, adults who are happily married, have higher educational attainment, experience low levels of stressors, or have self-reported good health all score low for suicidal ideation, that is, thoughts about suicide such as planning, role playing, or conducting unsuccessful attempts (Chin et al 2011). Conversely, those who experience higher levels of stressors or those who suffer from depression have much higher suicidal ideation scores (Chin et al 2011). The clinical negative affective states of depression and anxiety also correlate with both suicidal thinking and suicidal behaviours in youth (Verona \& Javdani 2011). It has also been suggested that in some cases, particularly in the elderly, depression is one of the main predictors of suicidal behaviour (Miret et al 2010).

\section{Are there animal examples of negative affect influencing mortality rates and longevity?}

Since animals lack the ability to report their own affective state in human language, we must make inferences based on other data. One way that animal affective states can be assessed is by examining the correlates of negative affect in humans, and applying them to animals. This would include assessing whether stimuli are preferred or avoided, and measuring the activity of the HPA and SAM axes, as previously mentioned. Other methods of assessing welfare are measuring levels of stereotypic behaviour (eg Mason et al 2007) and humans subjectively judging animals' qualitative states (eg Weiss et al 2011).

Several primate examples look at the consequences of breaking social bonds. Independent evidence has been provided here to show that the stressors mentioned below do cause negative affective states in animals. Social isolation of primates causes negative affective state, as evidenced by elevated basal cortisol concentrations after controlling for activity levels, compared to socially housed animals (Sapolsky et al 1997). Lewis et al (2000) examined the effects of early social isolation on rhesus macaques (Macaca mulatta); one group was socially isolated for the first nine months of life (infancy), while another group was raised in contact with other monkeys. After this period, the living conditions were identical for both groups, and their subsequent longevity was analysed. The early social deprivation group had a significantly decreased longevity: an effect evident only once the monkeys were ten years of age and older. Although not specifically measured, isolates were also noted as displaying more stereotypic behaviour (it has also been reported in such animals in other studies; see Novak et al [2006]; and isolation rearing is widely regarded as being poor for primate welfare, especially during infancy [Novak et al 2006]). Early maternal separation has also been related to increased mortality in another social species: captive Asian (Elephas maximus) elephants (Clubb et al 2009). Asian elephants tended to be separated from their mothers at half the median age of African (Loxodonta africana) elephants, and this result correlated with increased mortality rates among Asian elephants. It is important to note that these effects are not seen in infancy or even the juvenile period, but rather years later in mature adulthood.

In another example, Capitanio et al (1998) infected rhesus monkeys with simian acquired immune deficiency syndrome (SIV) and divided them into two treatment groups. The monkeys were housed individually, but were given three periods per day when they were put into social groups. One treatment represented stable social groups, where the same three individuals were always put together. The other treatment represented unstable social groups, with two to four varying members, such that the groups never had the same composition. This is likely to be aversive: increased basal cortisol secretion occurs in primates forced into new social groupings (independent of activity levels), suggesting negative affect (Gust et al 1992), and consistent with this, aggressive behaviours associated with negative affective states such as threatening and chasing (agonistic behaviour is associated with elevated noradrenaline and cortisol levels [Cohen et al 1997]), were much higher in the unstable groups, whereas affiliative behaviours associated with positive affective states, such as proximity and grooming, were significantly higher in the stable condition (higher levels of grooming are correlated with lower levels of glucocorticoids [Shutt et al 2007]). The mean lifespan following inoculation was significantly longer for monkeys in the stable social groups, suggesting that a negative affective state was responsible for increasing the pathogenesis of SIV in monkeys kept in unstable social groups. Similarly, number of inter-zoo transfers predicts mortality rates in captive elephants (Clubb et al 2008, 2009). Asian elephants were found to be transferred between zoos five times more frequently than Africans, a result that predicted significantly reduced Asian adult survivorship, specifically in the four years post transfer, 
controlling for birth origin. The stressors of being transferred include capture and transport, but also importantly include the breaking and forming of social bonds. Several social species suffer high mortality rates after being caught in the wild and brought into captivity. For example, Small and Demaster (1995) have identified an approximately 60day period of high mortality post capture for wild-caught bottlenose dolphins (Tursiops truncatus) and California sea lions (Zalophus californianus). Similarly, Mar (2007) has found that mortality rates in elephants captured from the wild can take up to eight years post capture to stabilise. There are additional accounts of excess mortality when animals are moved into a zoo where factors such as social stressors as well as exposure to new diets and diseases have been implicated (eg Tocidlowski et al 1997; Gozalo \& Montoya 1991). We therefore cannot say that the high mortality rates observed post capture are caused directly by the disruption of social bonds, but we propose that it may be a potential contributor to such outcomes. This topic certainly warrants further scientific attention.

Other cases illustrate the potentially adverse affective and survivorship effects of being subordinate. One classic study, briefly mentioned in the Introduction, was the first to show that social status among animals, here tree shrews, influences mortality rates (von Holst 1972). Dominant shrews were allowed to physically attack and subjugate inferior individuals. Subordinates were separated following the fights (which were repeated every 1-2 days to maintain the dominance relationship), but they could still see the dominant animal and subsequently, the subordinates spent almost all their time watching the victor with their tail-hair raised (a sign of sympathetic activation). Within two weeks, subordinates began to die from uraemia, which was interpreted to be due to renal vasoconstriction caused by high activity of the sympathetic nervous system. There was no evidence that any had died from wounds. Levels of social affiliation similarly predict longevity in semi-wild adult rabbits (Oryctolagus cuniculus) (von Holst et al 1999). Social interactions, corticosteroid levels, and baseline heart rate were measured to determine affective state. Dominant rabbits received the lowest levels of aggression and they experienced vastly more sociopositive interactions with females (eg mutual grooming, resting in direct contact) than subordinate rabbits. This lack of social support for subordinate rabbits and antagonism from dominant rabbits induced a negative affective state, indicated by their high levels of corticosterone and higher baseline heart rates. It was found that subordinate male rabbits had significantly shorter lives than their superiors. Specifically, dominant animals lived on average $30 \%$ longer, a difference of an entire breeding season. Wounds were not associated with the causes of death in this study. Similar effects can also occur in primates. Thus, low social ranking was correlated with increased mortality in a Kenyan primate research centre, where the untimely deaths of eight subordinate vervet monkeys (Cercopithecus aethiops) prompted post mortem inspections. Comparing the 'sudden death' monkeys to conspecifics euthanised for other purposes, necropsies revealed these subordinates had bite scars, and also two pathological signs of physiological stress: gastric ulcers and hippocampal degeneration of substantial degree and size (Uno et al 1989). A retrospective analysis of behavioural observations found that these monkeys had endured sustained prolonged stress from aggression by conspecifics, from which they were unable to escape, and which they also seemed unable to mitigate via appeasement signals. In the wild, vervet monkeys have ritualised gestures to signal subordination, but these were not performed by these captive-born animals. Finally, a similar albeit anecdotal example comes from cetaceans: behavioural studies of bottlenose dolphins at Atlantis Marine Park in Australia identified distinct hierarchical and primary bonding changes that seemed to result in the premature death of one individual (Waples \& Gales 2002). As a result of unstable groupings, there were increased physical (non-lethal) attacks against an ostracised dolphin, evidenced by toothraking scores. Changes in the physiological and behavioural patterns of the ostracised dolphin were indicated by stressinduced, negative affect indicators, such as altered blood chemistry of white blood cells, gastric ulcers, and loss of appetite and weight loss.

Other, non-social aspects of the captive environment can also be important. Carlstead et al (1999) compared 23 different zoos with black rhinoceros (Diceros bicornis) and found that scores for fear, as determined by the 'Emotions Profile Index' involving data collected from keepers on their charges' behaviours and temperaments, were positively correlated to the percent of the enclosure available for public viewing. Furthermore, it was found that past mortality rates were also positively correlated to the percent of the enclosure available to the public. Together, this suggests that rhinos experiencing higher levels of fear due to poor enclosure design have an increased mortality risk. Similarly, enclosure variables were found to be more predictive of mortality rates in captive red pandas (Ailurus fulgens) than climate, diet, and management practices. Specifically, public traffic flow was found to be the most significant predictor of adult mortality rates (Roberts 1989). Husbandry practices have also been found to influence mortality rates in captive golden-headed lion tamarins (Leontopithecus chrysomelas) (Steinmetz et al 2011). Tamarins kept in an outdoor free-roaming management system had significantly lower adult mortality rates than those kept in traditional indoor enclosures in a Swiss zoo. The indoor tamarins also had higher morbidity and more bite injuries, which indicate that the traditional indoor enclosure management system was a stressor. Survivorship has also been assessed for rats in enriched and non-enriched environments; enriched rats (Rattus norvegicus) live significantly longer (Narath et al 2001). Male rats that were given access to running wheels (a preferred enrichment) had significantly higher survivorship rates than rats forced to run similar distances on a treadmill, as well as rats that were fed to pair weight but did not have access to a running wheel. This suggests that independent of amount of exercise and bodyweight, positive

\section{2012 Universities Federation for Animal Welfare}


affect provided by this enrichment may play a causal role in increasing rat survivorship. Mason (2010) also reviews several cases where wild species that appear to adapt more or less well to captivity also have correspondingly lower or higher rates of mortality and morbidity.

Finally, other types of studies involve animals that are not exposed to differentially aversive experiences, but instead are assessed for individual differences in avoidance responses, stress physiology, or other variables that suggest differential affective states when faced with similar events or challenges. Norway rats, for example, were classified as neophilic (ie bold and exploratory) or neophobic (ie fearful and non-exploratory) after they were assessed via an exploration arena test at four and eight months old (Cavigelli \& McClintock 2003). This trait proved stable. Furthermore, neophobic rats were found to have a greater corticosterone response to the exploration arena test than their neophilic conspecifics. Neophobic rats went on to have significantly decreased longevity; in particular; effects that could only be seen after the rats had passed 'middle age'. Similarly, Dreschel (2010) collected data on pet dogs from their owners via an online survey, including many behavioural characteristics. After controlling for several confounding factors, such as breed, whether or not the dogs were well behaved, and whether or not they were neutered, fear of unfamiliar humans independently and significantly predicted decreased longevity. These studies suggest that negative affective state per se may play a causal role in reducing the longevity of animals. One similar study correspondingly suggests that positive affect can be protective too. Orangutans subjectively judged by their keepers to be 'happier' lived longer lives (Weiss et al 2011). The keepers filled out a questionnaire with information about the subject's frequency of positive versus negative moods, pleasure derived from social interaction, ability to achieve its goals, as well as how happy they would be if they were the orangutan. This information was then converted into a score for happiness and put into a statistical model, where several predictors of mortality were assessed. Mortality was determined over a period of seven years using data from the orangutan studbook. The authors concluded that happiness was significantly correlated to longevity, even after controlling for age, sex, species, and number of transfers between zoos.

\section{Mechanisms linking negative affect and mortality in animals}

Mechanisms that link negative affect to mortality in animals seem to be similar to those in humans. Therefore, we briefly examine the same three disease processes here: immunosuppression, cancer and cardiovascular disease. Selfharming behaviours are additionally mentioned, albeit extremely cautiously, as a further hypothetical link.

As in humans, immunosuppression can be induced by aversive events or stimuli. For example, social separation is a stressor associated with negative affect in Siberian hamsters (Phodopus sungorus); thus, isolated males have increased plasma cortisol levels, despite being no more active than socially housed conspecifics (Castro \& Matt
1997). Isolation in Siberian hamsters also slows rates of wound healing, an index of immune function as discussed before. To illustrate, Detillion et al (2004) made cutaneous wounds on hamsters, followed by immobilising each by a restraint in order to induce stress. One group of hamsters was returned to their socially paired housing while the other was kept in isolation. The socially housed hamsters had both lower cortisol levels and faster healing than their isolated peers. Likewise, according to numerous immunological measures (lymphocyte subsets and proliferation, natural killer cell activity, and cytokine production) the immune systems of rhesus macaques housed in social groups were found to function at a higher level than those who were socially isolated (Schapiro et al 2000). Furthermore, immunosuppression is implicated in some of the studies we reported previously. For example, primates infected with SIV and housed in unstable social groups have increased viral replication and accelerated systemic immunopathogenesis, compared to those infected with SIV but kept in stable social groups (Sloan et al 2007). Similarly, Lewis et al (2000) report that isolate-reared monkeys had a decrease in helper to suppressor T-cell ratio (indicative of impaired immune functioning), and although the precise causes of death were not noted in this study (nor was antibody production assessed), they hypothesise that the reason the isolate-reared monkeys died younger may have been due to the inability to fight off sub-clinical infections.

Again, just as in humans, the pathogenesis of carcinoma can also be increased by exposure to stressors and negative affect. Thus, in rodents, experimental stressors such as social isolation, restraint, forced swim, and surgery all increase the pathogenesis of various types of cancers including leukaemia, lymphoma, cervical and rectal cancer (reviewed by Antoni et al 2006). Similarly, crowded housing, and to a lesser extent isolated housing, both of which are stressors, can also promote tumour growth in male mice (Hasegawa \& Saiki 2002). Neophobic female Sprague-Dawley rats were found to have an increased risk of developing spontaneous cancerous tumours compared with their neophilic sisters, and as a result had decreased longevity (Cavigelli et al 2006). This represents one possible mechanism via which the neophobic rats in the previous section had accelerated mortality rates in old age.

Turning to disease states of the cardiovascular system, in one primate example, sympathetic arousal resulting from being continuously aggressive was implicated in the pathogenesis of atherosclerosis in cynomolgus macaques (Macaca fascicularis) housed in unstable social groups (reviewed by Kaplan and Manuck 1998). Furthermore, in a retrospective study, Shively et al (1989) analysed the incidence rates of coronary artery atherosclerosis (a precursor of myocardial infarction) in female cynomolgus monkeys housed either alone or in social groups. Isolates were housed in small cages designed for only one individual, whereas those in social groups were housed in larger cages with more open space. The incidence of atherosclerosis was found to be four times higher in the lone-housed females. Levels of physical activity were not assessed and 
this may have been a confounder here (see also 'false positives' in the Discussion), since less physical activity, which would be expected in socially isolated monkeys in small cages, is related to higher levels of cardiovascular disease (Powell et al 1987). However, the authors do mention that socially isolated monkeys tended to perform more stereotypic behaviour and that this may mean that isolates spent a similar time moving as those in social groups. While more clarity and specificity is needed here, it seems that, at the least, negative affective states play a partial role in the development of atherosclerosis in macaques. In addition, this topic has been reviewed by Alboni and Alboni (2006), where social isolation and subordination have been found to predict higher levels of atherosclerosis in numerous social species.

Finally, can extremely negative affective states lead animals to perform potentially fatal behaviours? This controversial, speculative suggestion has been made several times. For example, in the case of the socially ostracised dolphin at Atlantis Marine Park (see Waples \& Gales [2002] above), the necropsy revealed asphyxiation to be the cause of death. Since dolphins are conscious breathers (Ridgway et al 1971), this suggests that this individual voluntarily stopped breathing - a suggestion that was similarly made for the dolphin that played the part of 'Flipper' in the eponymous 1960's TV show (Nobel 2010). However, the hypothesis that severe stressors may lead to suicide in animals, just as they can in humans, has yet to be tested. Evidence for this hypothesis would require showing that animals in severely aversive conditions become motivated to seek danger or perform self-harming behaviours, and more challengingly, that this is done with an understanding of the risk of death.

\section{Discussion}

Mortality rates have often been used in population-level animal welfare assessments, where they are implicitly viewed as arising from past unpleasant states such as being diseased, injured or malnourished; here, poor welfare and high mortality correlate because both are the consequences of physical harm. This review, however, highlights a further reason to use mortality rates to infer past poor welfare: that negative affective states can enhance mortality via a direct causal route, preceding and then actually elevating morbidity and mortality. Such effects can occur even with negative affective states that do not arise from physical harm (ie from such psychological stressors as fear, anxiety and loneliness). Negative affective states act in this way via dramatic or sustained physiological consequences which then cause or accelerate harmful somatic effects such as compromised immune function, the progression of cancer, and cardiovascular disease. In some instances they may also act to induce self-harm. Furthermore, as we have seen, these consequences may occur quite quickly following a severe stressor; alternatively, early life events may have delayed effects, or chronic conditions may have accumulating effects.

Overall, these findings therefore suggest that in animal populations with higher than expected mortality rates, psychological stressors such as fear, anxiety and loneliness may be contributing alongside primary infectious diseases, injury or malnourishment. Thus, when populations differ in mortality rates, as they do in zoo populations of tigers (Panthera tigris sumatra) for example (Mace \& Pelletier 2007), differential exposure to disease risks, risks of injury or poor diets may be the explanation, but differential exposure to psychological stressors such as social instability or fearful stimuli may instead be the crucial causes. These findings also suggest that in populations suffering from such physical harms as disease, injury or malnourishment, the negative affective states that result (eg pain or malaise) may actually act to enhance the lethality of these physical harms. As a possible example, Asiatic black bears (Ursus thibetanus) that are farmed for bile rarely reach ten years of age, whereas in Western facilities, bears are known to live beyond 30 years (Loeffler et al 2009). Disease is one well-known cause: bears often become infected from their gall bladder fistulations. States such as fear or frustration could also play a direct role: confined in cages barely bigger than the bears themselves, stereotypic behaviours occur in over $95 \%$ of bears (a prevalence much higher than occurs in zoos), and in some cases so extreme that self-mutilation results (again much more severe than occurs in zoos). Finally, the experience of pain from this self-harm, from the infections, or from injuries (many bears have clipped teeth with exposed nerves for example), could further act to accelerate their mortality rates. It should be noted however that it is very difficult to tease apart the relative contributions of psychological stressors and physical ailments (ie infections) to mortality in this case.

While mortality rates can reflect past poor welfare, as we have argued, not all differences in mortality rate reflect past negative affect, and all states of negative affect do not always induce elevated mortality. In this last section we therefore consider the 'false positives' and 'false negatives' that may be encountered by those wishing to use mortality rates to make inferences about past welfare. In doing so we also highlight how such approaches may be more useful for some types of animals (namely those that are allowed to live out their natural lifespans) than others.

Examples of 'false positives', where elevated mortality rates do not reflect past poor welfare, include cases where risk factors for premature death are neutral or even positive with respect to welfare. In humans, thrill-seeking behaviours, being male, not exercising, and over-eating all enhance mortality rates and reduce longevity. Thus, humans with a 'sex, drugs, and rock'n'roll' lifestyle may experience positive affect, and yet still are liable to experience increased morbidity and mortality because these behaviours bring risks (eg high levels of promiscuity are correlated with increased HIV prevalence; Kyriakis and Hadjivassiliou 2000). In animal studies, sex is therefore likely to be a confound: sex-specific mortality rates should not be interpreted as reflecting sex differences in affective state. Obesity and exercise levels may also be confounds. For example, mice (Mus musculus) in four common inbred strains that were heavier at ages 2-24 months had significantly shorter lifespans, despite identical living conditions (Miller et al 2002); while rodents exposed to forced

\footnotetext{
( 2012 Universities Federation for Animal Welfare
} 
exercise live longer even though forced exercise may be stressful (eg Drori \& Folman 1976). Thus, in zoo elephants, for example, while the shortened adult lifespans of zoohoused Asians and Africans, compared with in situ conspecifics, could reflect poor welfare, they could equally reflect the greater fat levels of these animals (Clubb et al 2009; Mason \& Veasey 2010). Similarly, male rats that are allowed to mate are seen to live significantly longer (by an average of 156 days) than those that are not (Drori \& Folman 1969). This may reflect that the act of mating leads to positive affective states, but equally, it could merely reflect that mating stimulates exercise, which is known to prolong rats' lifespans. Genetics can also reduce longevity in some cases, independent of affective state. For example, larger dogs live shorter lives than smaller dogs, as do pure breeds compared with mongrels (Patronek et al 1996); species also differ greatly in their intrinsic natural lifespans, in a way that often reveals nothing about differential welfare (eg Mason 2010).

Examples of false negatives are cases where negative affect fails to be detectable via changes in mortality. The most obvious example of this is that extended lifespan and reduced mortality rates may not indicate improved welfare or enhanced positive affect when there are medical or veterinary interventions that can greatly extend life without necessarily reflecting or even causing better welfare (examples here might include humans on life-support systems, or much loved pets that are kept alive despite chronically harmful conditions).

In other instances false negatives might occur because the physiological effects of a stressor need to be large and/or prolonged for extended periods of time in order to induce elevated morbidity, let alone elevated mortality. This means that minor changes in affective state are unlikely to translate into mortality effects, suggesting that this index has low sensitivity, especially for mild stressors. In other instances this might occur because the harmful effects are delayed in their manifestation, and/or only accumulate over a long period of time, such that they are only detectable at the end of life - sometimes many years distant from the stressor. The neophobic rats, isolate-reared macaques, and early weaned elephants among other examples seem to suggest that the mechanisms involve the delayed or gradual accumulation of harmful effects rather than reflecting immediate effects of a physiological stressor response. Therefore, if the mortality rates of the animals in these examples were assessed when they were too young, or too soon after an imposed stressor, one might erroneously infer that they had the same welfare as control subjects. Consequently, this risk of false negatives could mean that using mortality rates to infer past negative affect has limited application in populations that are killed when they are young. Therefore, we suggest that mortality rates are least useful in identifying lifetime welfare in populations of animals that tend to be euthanised prematurely, such as farm and lab animals. The exceptions to this of course are the breeding stocks, which in both cases are often kept until they reach middle age or even senescence. We propose that the index has the greatest potential for use in husbandry settings where animals tend to be allowed to live out their full lives, namely for zoo (eg Clubb et al 2008, 2009; Müller et al 2009) and companion animals (eg Dreschel 2010). However, this is not to say that the use of mortality rates to infer welfare is strictly confined to certain husbandry settings. In any population of captive (or domestic) animals where there is higher than expected mortality rates, poor welfare may play a causal role.

\section{Conclusion}

Here, we presented evidence that negative affective states can be related to mortality via causal rather than merely correlational routes. Specifically, negative physiological effects such as compromised immune function, cardiovascular disease, and cancer are known to be caused by, or accelerated by, negative affect and may lead to increased mortality and decreased longevity in both humans and animals. Caution should be exercised in interpreting mortality data without first addressing the possible sources of error listed above. Mortality would be best used in conjunction with other possible indices of welfare (eg von Holst et al 1999), in order to ensure that the inferences made about affect are correct. Mortality is easy to measure and requires no technical equipment or expertise beyond statistics. One area where this might be particularly useful is in a zoo setting. Using mortality and longevity data, one can make cross-facility comparisons which have the potential to vastly improve zoo animal welfare by implementing the best strategies in enclosure design and management practices. The downside however is that the results are too late for the animals they came from, and can only be used to improve the welfare of other conspecifics. Overall, it seems that mortality and longevity have the potential to be valid indices of animal welfare and can be useful tools in assessing the ability of different husbandry systems to provide good welfare for animals.

\section{Acknowledgements}

We would like to thank NSERC for funding this work, as well as three helpful reviewers for their comments and improvements to this article.

\section{References}

Aaltonen K, Bryant AA, Hostetler JA and Oli MK 2009 Reintroducing endangered Vancouver Island marmots: survival and cause-specific mortality rates of captive-born versus wildborn individuals. Biological Conservation 142: 218I-2190. http://dx.doi.org/10.1016/j.biocon.2009.04.019

Alboni P and Alboni M 2006 Psychosocial factors as predictors of atherosclerosis and cardiovascular events: contributions from animal models. Giornale Italiano Cardiologia 7(II): 747-753

Anda R, Williamson D, Jones D, Macera C, Eaker E, Glassman A and Marks J 1993 Depressed affect, hopelessness, and the risk of ischemic heart disease in a cohort of U.S. adults. Epidemiology 4(4): 285-294. http://dx.doi.org/10.1097/00001648199307000-00003

Antoni MH, Lutgendorf SK, Cole SW, Dhabhar FS, Sephton SE, McDonald PG, Stefanek M and Sood AK 2006 The influence of bio-behavioural factors on tumour biology: pathways and mechanisms. Nature Reviews Cancer 6(3): 240-248. http://dx.doi.org//0.1038/nrc1820 
Berkman L, Leo-Summers L and Horwitz R 1992 Emotional support and survival after myocardial infarction. Annals of Internal Medicine I/ 7( / 2): 1003-1009

Capitanio J, Mendoza S, Lerche N and Mason W 1998 Social stress results in altered glucocorticoid regulation and shorter survival in simian acquired immune deficiency syndrome. Proceedings of the National Academy of Science 95: 47/4-47I9. http://dx.doi.org//0.1073/pnas.95.8.47/4

Carlstead K, Fraser J, Bennet C and Kleiman D 1999 Black rhinoceros (Diceros bicornis) in U.S. zoos: II. behaviour, breeding success, and mortality in relation to housing facilities. Zoo Biology 18: 35-52. http://dx.doi.org//0.1002/(SICI) 1098-236I (1999) I8:I $<35:: A I D-Z O O 5>3.0 . C O ; 2-L$

Castro WLR and Matt KS 1997 Neuroendocrine correlates of separation stress in the Siberian Dwarf Hamster (Phodopus sungorus). Physiology \& Behaviour 61: 477-484. http://dx.doi.org/l0. I016/S0031-9384(96)00456-8

Cavigelli SA and McClinktock MK 2003 Fear of novelty in infant rats predicts adult corticosterone dynamics and an early death. PNAS 100(26): 16131-16136. http://dx.doi.org/l0. 1073/pnas.2535721100

Cavigelli SA, Yee JR and McClintock MK 2006 Infant temperament predicts life span in female rats that develop spontaneous tumors. Hormones and Behavior 50: 454-462. http://dx.doi.org/10.1016/j.yhbeh.2006.06.00I

Chauvin C, Hillion S, Balaine L, Michel V, Peraste J, Petetin I, Lupo C and Le Bouquin S 20I I Factors associated with mortality of broilers during transport to slaughterhouse. Animal 5(2): 287-293. http://dx.doi.org/l0.1017 ISI751731II0001916

Chin $\mathbf{Y}$, Lee $\mathbf{H}$ and So E 201 I Suicidal ideation and associated factors by sex in Korean adults: a population based cross-sectional survey. International Journal of Public Health 56(4): 429-439. http://dx.doi.org/ I0.1007/s00038-0 I I-0245-9

Christensen NJ and Galbo H 1983 Sympathetic nervous activity during exercise. Annual Review of Physiology 45: 139-153. http://dx.doi.org/10.1 I46/annurev.ph.45.030183.001035

Clubb R, Rowcliffe M, Lee P, Mar K, Moss C and Mason G 2008 Compromised survivorship in zoo elephants. Science 322: 1649. http://dx.doi.org/ I0.1 I 26/science. I I64298

Clubb R, Rowcliffe M, Lee P, Mar K, Moss C and Mason G 2009 Fecundity and population viability in female zoo elephants: problems and possible solutions. Animal Welfare 18: 237-247

Cohen S, Line S, Manuck SB, Rabin BS, Heise ER and Kaplan JR 1997 Chronic social stress, social status, and susceptibility to upper respiratory infections in nonhuman primates. Psychosomatic Medicine 59: 213-221

Costa D and Kahn M 2010 Health, wartime stress, and unit cohesion: evidence from Union Army veterans. Demography 47(I): 45-66. http://dx.doi.org// 0.1353/dem.0.0095

Dawkins MS 1988 Behavioural deprivation: a central problem in animal welfare. Applied Animal Behaviour Science 20: 209-225. http://dx.doi.org/I0.1016/0168-I591(88)90047-0

Detillion C, Craft T, Glasper E, Prendergast B and DeVries A 2004 Social facilitation of wound healing. Psychoneuroendocrinology 29: 1004-1011. http://dx.doi.org/ 10.1016/j.psyneuen.2003.10.003
Diener E and Chan MY 20I I Happy people live longer: subjective well-being contributes to health and longevity. Applied Psychology: Health and Well-Being 3: 1-43. http://dx.doi.org/I0.IIII/j.1758-0854.2010.01045.x

Donaldson R 2003 Experiences of older burglary victims. Home Office: Research, Development, and Statistics Directorate 198: I-4

Dreschel NA 2010 The effects of fear and anxiety on health and lifespan in pet dogs. Applied Animal Behaviour Science 125(3-4): I57162. http://dx.doi.org/ 10.1016/j.applanim.2010.04.003

Drori D and Folman Y 1969 The effect of mating on the longevity of male rats. Experimental Gerontology 4: 263-266. http://dx.doi.org//0.1016/0531-5565(69)90014-X

Drori D and Folman Y 1976 Environmental effects on longevity in the male rat: exercise, mating, castration, and restricted feeding. Experimental Gerontology II: 25-32. http://dx.doi.org/I0.1016/0531-5565(76)90007-3

Duncan IJH 2006 The changing concept of animal sentience. Applied Animal Behaviour Science 100: 11-19. http://dx.doi.org/10.1016/j.applanim.2006.04.01 I

Evans DL, Leserman J, Perkins DO, Stern RA, Murphy C, Zheng B, Gettes D, Longmate JA, Silva SG, van der Horst CM, Hall CD, Folds JD, Golden RN and Petitto JM 1997 Severe life stress as a predictor of early disease progression in HIV infection. American Journal of Psychiatry 154: 630-634

Everson SA, Kaplan GA, Goldberg DE, Salonen R and Salonen JT 1997 Hopelessness and 4-year progression of carotid atherosclerosis: the Kuopio ischemic heart disease risk factor study. Arteriosclerosis Thrombosis and Vascular Biology 17(8): |490-1495. http://dx.doi.org/I0.1 I6I/0I.ATV.17.8.1490

Fang F, Fall K, Sparén P, Adami H, Valdimarsdóttir H, Lambe $M$ and Valdimarsdóttir $O 2010$ Risk of infection-related cancers after the loss of a child: a follow-up study in Sweden. Cancer Research 71: I16-122

Friedmann E, Thomas S, Liu F, Morton P, Chapa D and Gottlieb S 2006 Relationship of depression, anxiety, and social isolation to chronic heart failure outpatient mortality. American Heart Journal 152: 940. http://dx.doi.org// 0.1016/j.ahj.2006.05.009 Gozalo A and Montoya E 1991 Mortality causes of the moustached tamarin (Saguinus mystax) in captivity. Journal of Medical Primatology 21: 35-38

Guba M, Graeb C, Jaunch K and Geissler E 2004 Pro- and anti-cancer effects of immunosuppressive agents used in organ transplantation. Transplantation 77: I777-I782. http://dx.doi.org/I0.1097/0I.TP.0000 I20181.89206.54

Gust DA, Gordon TP, Wilson ME, Brodie AR, AhmedAnsari A and McClure HM 1992 Removal from natal social group to peer housing affects cortisol levels and absolute numbers of $\mathrm{T}$ cell subsets in juvenile rhesus monkeys. Brain, Behaviour, and Immunity 6: 189-199. http://dx.doi.org/10.1016/0889I59I(92)90018-J

Hasegawa H and Saiki I 2002 Psychosocial stress augments tumor development through $\beta$-adrenergic activation in mice. Japanese Journal of Cancer Research 93: 729-735. http://dx.doi.org/10.1 I I I/j.1349-7006.2002.tb0 I3 I3.x

Jacob F, Polzin DJ, Osborne CA, Neaton JD, Kirk CA, Allen TA and Swanson LL 2005 Evaluation of the association between initial proteinuria and morbidity rate or death in dogs with naturally occurring chronic renal failure. Journal of the American Veterinary Medical Association 226(3): 393-400. http://dx.doi.org// 0.2460/javma.2005.226.393 
Kaplan JR and Manuck SB 1998 Monkeys, aggression, and the pathobiology of atherosclerosis. Aggressive Behavior 24(4): 323334. http://dx.doi.org/10.1002/(SICl) 1098-2337(1998)24:4<323:: AID-AB7>3.0.CO;2-J

Kawachi I, Colditz G, Ascherio A, Rimm E, Giovanucci E, Stampfer M and Willett W 1992 Prospective study of phobic anxiety and risk of coronary heart disease in men. Circulation 89(5): 1992-1997. http://dx.doi.org/I0.I I6I/0I.CIR.89.5.1992

Kiecolt-Glaser J, Marucha P, Malarkey W, Mercado A and Glaser R 1995 Slowing of wound healing by psychological stress. The Lancet 346: II94-II96. http://dx.doi.org/l0.1016/S01406736(95)92899-5

Kirk SJ, Hurson M, Regan MC, Holt DR, Wasserkrug HL and Barbul A 1993 Arginine stimulates wound healing and immune function in elderly human beings. Surgery I/ 4: I55-160

Kubzansky LD, Davidson KW, and Rozanski A 2005 The clinical impact of negative psychological states: expanding the spectrum of risk for coronary artery disease. Psychosomatic Medicine 67: SI0-SI4. http://dx.doi.org//0.10 97/0I.psy.00001640I2.88829.4I

Kyriakis K and Hadjivassiliou M 2000 HIV-I infection-associated risk factors among sexually transmitted disease patients in Athens, Greece: 1990-1996. Sexually Transmitted Diseases 27(5): 259-265. http://dx.doi.org/10.1097/00007435-200005000-00004

Leserman J 2003 HIV disease progression: depression, stress, and possible mechanisms. Biological Psychiatry 54: 295-306. http://dx.doi.org/10.1016/S0006-3223(03)00323-8

Leserman J 2008 Role of depression, stress, and trauma in HIV disease progression. Psychosomatic Medicine 70(5): 539-545. http://dx.doi.org/10.1097/PSY.0b013e3181777a5f

Lewis M, Gluck J, Petitto J, Hensley L and Ozer H 2000 Early social deprivation in nonhuman primates: long-term effects on survival and cell-mediated immunity. Biological Psychiatry 47: I 19-126. http://dx.doi.org/10.1016/S0006-3223(99)00238-3

Lillberg K, Verkasalo PK, Kaprio J, Teppo L, Helenius H and Koskenvuo M 2003 Stressful life events and risk of breast cancer in 10,808 women: a cohort study. American Journal of Epidemiology 157(5): 4/5-423. http://dx.doi.org//0.109 3/aje/kwg002

Loeffler I, Robinson J and Cochrane G 2009 Compromised health and welfare of bears farmed for bile in China. Animal Welfare 18: 225-235

Mace G and Pelletier F 2007 Commentary on Ricklefs and Cadena (2007): reproductive investment and lifespan. Ecology Letters 10(/0): 872-874. http://dx.doi.org/I0.IIII/j.I46I0248.2007.01097.x

Mar K 2007 The demography and life history strategies of timber elephants in Myanmar. PhD Thesis, University of London, London, UK Marmot MG, Rose G, Shipley M and Hamilton PJ 1978 Employment grade and coronary heart disease in British civil servants. Journal of Epidemiology and Community Health 32: 244-249. http://dx.doi.org/I0.I I36/jech.32.4.244

Mason G 2010 Species differences in response to captivity: stress, welfare, and the comparative method. Trends in Ecology and Evolution 25(I2): 713-72I. http://dx.doi.org/I0.10 16/j.tree.2010.08.011

Mason G, Clubb R, Latham N and Vickery S 2007 Why and how we should use environmental enrichment to tackle stereotypic behaviour. Applied Animal Behaviour Science 102(3-4): 163188. http://dx.doi.org/ I0.1016/j.applanim.2006.05.04 I
Mason G and Mendl M 1993 Why is there no simple way of measuring animal welfare? Animal Welfare 2: 301-319

Mason G and Veasey J 2010 What do population-level welfare indices suggest about the well-being of zoo elephants? Zoo Biology 29(2): 256-273

McEwen B 2005 Stressed or stressed out: What is the difference? Journal of Psychiatry and Neuroscience 30: 315-318

Miller RA, Harper JM, Galecki A and Burke DT 2002 Big mice die young: early life body weight predicts longevity in genetically heterogeneous mice. Aging Cell 1 : 22-29. http://dx.doi.org/I0.1046/j. I474-9728.2002.00006.x

Miret M, Nuevo R, Morant C, Sainz-Corton E, JimenezArrierro MA, Lopez-Ibor JJ, Reneses B, Saiz-Ruiz J, BacaGarcia E and Ayuso-Mateos JL 2010 Differences between younger and older adults in the structure of suicidal intent and its correlates. American Journal of Geriatric Psychiatry 18(9): 839-847. http://dx.doi.org// 0.1097/JGP.0b0 I 3e3 I8Id I45b0

Moskowitz JT 2003 Positive affect predicts lower risk of AIDS mortality. Psychosomatic Medicine 65: 620-626. http://dx.doi.org/I0.1097/0 I.PSY.0000073873.74829.23

Müller DWH, Gaillard J, Lackey LB, Hatt J and Clauss M 2009 Comparing life expectancy of three deer species between captive and wild populations. European Journal of Wildlife Research 56: 205-208

Munoz MJ and Riddle DL 2003 Positive selection of Caenorhabditis elegans mutants with increased stress resistance and longevity. Genetics 163: I7I-180

Murphy JM, Olivier DC, Monson RR, Sobol AM, Federman EB and Leighton AH 1991 Depression and anxiety in relation to social status. Archives of General Psychiatry 48: 223-229. http://dx.doi.org/10.1001/archpsyc.1991.018102700 35004

Naess H, Lunde L, Brogger J and Waje-Andreassen $\mathbf{U}$ 2010 Depression predicts unfavourable functional outcome and higher mortality in stroke patients: the Bergen Stroke Study. Acta Neurologica Scandinavica 122(190): 34-38. http://dx.doi.org//0.1 I II/j.1600-0404.2010.01373.x

Narath E, Skalicky M and Viidik A 200I Voluntary and forced exercise influence the survival and body composition of aging male rats differently. Experimental Gerontology 36(10): 1699-I71।. http://dx.doi.org/I0.1016/S053I-5565(01)00145-0

Neugebauer V, Li W, Bird GC and Han JS 2004 The amygdale and persistent pain. Neuroscientist 10(3): 221-234. http://dx.doi.org//0.1 I77/107385840326/077

Nobel J 2010 Do animals commit suicide? A scientific debate. TIME Magazine; March 19, 2010.

Novak M, Meyer J, Lutz C and Tiefenbacher S 2006 Deprived environments: developmental insights from primatology. In: Mason G and Rushen J (eds) Stereotypic Animal Behaviour: Fundamentals and Applications to Welfare, Second Edition PP 153190. CABI: Wallingford, Oxon, UK

Patronek G, Waters D and Glickman L 1996 Comparative longevity of pet dogs and humans: implications for gerontology research. The Journal of Gerontology 52A(3): BI7I-BI78

Pennix BWJH, Guralnik JM and Havlik RJ 1998 Chronically depressed mood and cancer risk in older persons. Journal of the National Cancer Institute 90(24): 1888-1893. http://dx.doi.org//0.I 093/jnci/90.24.1888 
Powell KE, Thompson PD, Caspersen CJ and Kendrick JS 1987 Physical activity and the incidence of coronary heart disease. Annual Review of Public Health 8: 235-287. http://dx.doi.org/10.1 I46/annurev.pu.08.050187.001345

Ridgway SH and McCormick JG 197 I Anesthesia of the porpoise. In: Soma LR (ed) Textbook of Veterinary Anesthesia PP 394-403. Williams \& Wilkins: Baltimore, USA

Roberts M 1989 A survey and analysis of management practices in the North American Red Panda population. In: Glaston AR (ed) Red Panda Biology PP 129-I5I. SPB Academic Publishing: The Hague, The Netherlands

Rosengren A, Hawken S, Ounpuu S, Sliwa K, Zubaid M, Almahmeed WA, Blackett KN, Sitthi-amorn C, Sato H and Yusuf S 2004 Association of psychosocial risk factors with acute myocardial infarction in IIII9 cases and 13648 controls from 52 countries (the INTERHEART study): case-control study. The Lancet 364: 953-962. http://dx.doi.org/10.1016/S01406736(04)17019-0

Rovner BW, German PS, Brant LJ, Clark R, Burton L and Folstein MF 1991 Depression and mortality. The Journal of the American Medical Association 265: 993-996. http://dx.doi. org/10.1001/jama.1991.03460080063033

Rushen J 1986 Aversion of sheep to electro-immobilization and physical restraint. Applied Animal Behaviour Science 15: 315-324. http://dx.doi.org/10.1016/0168-1591(86)90124-3

Russell JA 2003 Core affect and the psychological construction of emotion. Psychological Review 1/0: 145-172. http://dx. doi.org/10.1037/0033-295X.I10.1.145

Saino N, Ambrosini R, Martinelli R and Moller AP 2002 Mate fidelity, senescence in breeding performance and reproductive trade-offs in the barn swallow. Journal of Animal Ecology $7 \mathrm{I}$ : 309-319. http://dx.doi.org/10.1046/j.1365-2656.2002.00600.x

Sapolsky RM, Alberts SC and Altmann J 1997 Hypercortisolism associated with social subordinance or social isolation among wild baboons. Archives of General Psychology 54: I|37-1|43. http://dx.doi.org/10.1001/archpsyc.1997.018302 40097014

Satin JR, Linden W and Phillips MJ 2009 Depression as a predictor of disease progression and mortality in cancer patients. Cancer I I5(22): 5349-536I. http://dx.doi.org/I0.1002/cncr.2456 I

Schaefer C, Coyne JC and Lazarus RS I98I The health-related functions of social support. Journal of Behavioral Medicine 4: 38 I-486. http://dx.doi.org/ I0.1007/BF00846 I49

Schapiro SJ, Nehete PN, Perlman JE and Sastry KJ 2000 A comparison of cell-mediated immune responses in rhesus macaques housed singly, in pairs, or in groups. Applied Animal Behaviour Science 68: 67-84. http://dx.doi.org/10.1016/S0168I59|(00)00090-3

Shively C, Clarkson T and Kaplan J 1989 Social deprivation and coronary artery atherosclerosis in female cynomolgus monkeys. Atherosclerosis 77: 69-76. http://dx.doi.org/10.1016/00219150(89)900। I-7

Shutt K, MacLarnon A, Heistermann $M$ and Semple S 2007 Grooming in barbary macaques: better to give that to receive? Biology Letters 3: 23I-233.http://dx.doi.org/I0.I 098/rsbl.2007.0052
Sinha R, Talih M, Malison R, Cooney N, Anderson GM and Kreek MJ 2003 Hypothalamic-pituitary-adrenal axis and sympatho-adreno-medullary responses to stress-induced and drug cue-induced cocaine craving states. Psychopharmacology 170: 62-72. http://dx.doi.org//0.1007/s00213-003-1525-8

Sirois BC and Burg MM 2003 Negative emotion and coronary heart disease. A review. Behaviour Modification 27: 83-102. http://dx.doi.org//0.1 I77/0145445502238695

Sloan EK, Capitanio JP, Tarara RP, Mendoza SP, Mason WA and Cole SW 2007 Social stress enhances sympathetic innervation of primate lymph nodes: mechanisms and implications for viral pathogenesis. Journal of Neuroscience 27(33): 8857-8865. http://dx.doi.org/ I0.1523/JNEUROSCI.I247-07.2007

Small RJ and Demaster DP 1995 Acclimation to captivity: a quantitative estimate based on survival of bottle-nosed dolphins and California sea lions. Marine Mammal Science II(4): 510-5I9. http://dx.doi.org/10.1 I I I/j.1748-7692.1995.tb00674.x

Sood AK, Hatty RB, Kamat AA, Landen CN, Han L, Thaker PM, Li Y, Gerhenson DM, Lutgendorf S and Cole SW 2006 Stress hormone-mediated invasion of ovarian cancer cells. Clinical Cancer Research 12: 369-375. http://dx.doi.org/ 10.1 I58/I078-0432.CCR-05-1698

Spruijt BM, van den Bos R and Pijlman FT 200I A concept of welfare based on reward evaluating mechanisms in the brain: anticipatory behaviour as an indicator for the state of reward systems. Applied Animal Behaviour Science 72: 145-17|. http://dx.doi.org/10.1016/S0168-1591(00)00204-5

Steinmetz HW, Zingg R, Ossent P, Eulenberger $U$, Clauss $M$ and Hatt JM 20 I I Comparison of indoor and captive, free-roaming management in golden-headed lion tamarins (Leontopithecus chrysomelas) at Zurich zoo. Animal Welfare 20(2): 205-210

Stern SL, Dhanda R and Hazuda HP 200I Hopelessness predicts mortality in older Mexican and European Americans. Psychosomatic Medicine 63(3): 344-35I

Takkouche B, Regueira C and Gestal-Otero J 2001 A cohort study of stress and the common cold. Epidemiology 12: 345-349. http://dx.doi.org/I0.1097/0000 I648-200105000-000I5 Tocidlowski ME, Cornish TE, Loomis MR and Stoskopf MK 1997 Mortality in captive wild-caught horned puffin chicks (Fratercula corniculata). Journal of Zoo and Wildlife Medicine 28: 298-306

Tsigos C and Chrousos GP 2002 Hypothalamic-pituitary-adrenal axis, neuroendocrine factors and stress. Journal of Psychosomatic Research 53(4): 865-871. http://dx.doi.org/l0. 1016/S0022-3999(02)00429-4

Uno H, Tarara R, Else J, Suleman M and Sapolsky R 1989 Hippocampal damage associated with prolonged and fatal stress in primates. The Journal of Neuroscience 9: 1705-171।

Verona E and Javdani S 20 I I Dimensions of adolescent psychopathology and relationships to suicide risk indicators. Journal of Youth and Adolescence 40(8): 958-971. http://dx.doi.org/l0. 1007/s 10964-0I I-9630-I

Vigliola L and Meekan MG 2002 Size at hatching and planktonic growth determine post-settlement survivorship of coral reef fish. Oecologia 131: 89-93. http://dx.doi.org//0.1007/s00442-00I0866-4

von Holst D 1972 Renal failure as the cause of death in Tupaia belangeri exposed to persistent social stress. Journal of Comparative Physiology A78: 236-273. http://dx.doi.org/ I0.1007/BF00697657 
von Holst D, Hutzelmeyer H, Kaetzke P, Khaschei $M$ and Shonheiter R 1999 Social rank, stress, fitness, and life expectancy in wild rabbits. Naturwissenschaften 86: 388-393

Waples $K$ and Gales $\mathbf{N} 2002$ Evaluating and minimising social stress in the care of captive bottlenose dolphins (Tursiops aduncus). Zoo Biology 21: 5-26. http://dx.doi.org/10.1002/zoo.10004

Weiss A, Adams MJ and King JE 20I I Happy orang-utans live longer lives. Biology Letters 7(6): 872-874. http://dx.doi.org/10.1098/rsbl.201 I.0543

Wickrama K, Lorenz F, Conger R and Elder G 1997 Marital quality and physical illness: a latent growth curve analysis. Journal of Marriage and Family 59: 143-155. http://dx.doi.org/l0. $2307 / 353668$
Wilson R, Bienias J, Mendes de Leon C, Evans D and Bennett D 2003 Negative affect and mortality in older persons. American Journal of Epidemiology 158: 827. http://dx.doi.org/I0.1093/aje/kwg224

Yang EV, Kim S, Donovan EL, Chen M, Gross AC, Marketon JIW, Barsky SH and Glaser R 2009 Norepinephrine upregulates VEGF, IL-8, and IL-6 expression in human melanoma tumor cell lines: implications for stress-related enhancement of tumor progression. Brain, Behaviour, and Immunity 23(2): 267-275. http://dx.doi.org//0.1016/j.bbi.2008.10.005

Yun AJ, Lee PY and Bazar KA 2004 Temporal variation of autonomic balance and diseases during circadian, seasonal, reproductive, and lifespan cycles. Medical Hypotheses 63: 155-162. http://dx.doi.org//0.1016/j.mehy.2004.02.030 